\title{
Author Correction: Compact pebbles and the evolution of volatiles in the interstellar comet 2l/Borisov
}

Bin Yang (iD, Aigen Li (iD, Martin A. Cordiner (D), Chin-Shin Chang (iD), Olivier R. Hainaut (D), Jonathan P. Williams, Karen J. Meech, Jacqueline V. Keane and Eric Villard

Correction to: Nature Astronomy https://doi.org/10.1038/s41550-021-01336-w, published online 30 March 2021.

In the version of this Article originally published, Eric Villard was missing affiliation 1 'European Southern Observatory, Vitacura, Santiago, Chile'; this has now been corrected in all versions of the Article.

Published online: 19 April 2021

https://doi.org/10.1038/s41550-021-01367-3

() The Author(s), under exclusive licence to Springer Nature Limited 2021 